\title{
Clinical Recognition of Leprosy: Some Factors Leading to Delays in Diagnosis
}

\author{
SHEILA POWELL, COLIN MCDOUGALL
}

\section{Summary}

The case histories of eight patients in the United Kingdom admitted to hospital for the diagnosis of leprosy are examined in detail. Review of their early symptoms and signs showed that there had been delays in diagnosis, ranging from a few months to many years. Possible reasons for delay are discussed, and attention is called to the importance of nasal symptoms in the early diagnosis of lepromatous leprosy.

\section{Introduction}

The diagnosis of early leprosy is by no means easy. Its gradual onset and often chronic course and the widely varying spectrum between its tuberculoid and lepromatous poles may add to the difficulty. Awareness of the disease, both in Britain and abroad, may not have improved much since an eminent authority wrote: "Today leprosy is in the same position that tuberculosis was 30 years ago, and the diagnosis of leprosy is always, or almost always, made too late. . . ." (Cochrane, 1965). In endemic areas, where diagnostic skill may be limited, it is still not uncommon to find conditions such as discoid lupus, psoriasis, or neurofibromatosis under full dapsone treatment in a leprosarium. Nevertheless, a total failure to recognize leprosy is much more common. Many authors (Cochrane, 1947; Jopling, 1956 and 1970; Fasal, 1958; Khanolkar, 1961) have noted the general difficulties of diagnosis, and particular emphasis has been given to the elusive appearance of early diffuse leprosy of the lepromatous type (Davey, 1942; Browne, 1965; Donner and Shively, 1967; Pfaltzgraff, 1967). In most branches of medicine there are recurrent reports of delays and difficulties in diagnosis, often from centres of high clinical standing (Boon and De Bye, 1969; Canizares and Andrade, 1969; Sinkovics and Ibanez, 1970). This paper presents the case histories of eight patients in whom the diagnosis of leprosy was delayed for periods of from a few months to many years, and draws attention to factors which may avent delay in a disease in which early recognition is particularly important.

\section{Case Reports}

Case 1.-A 19-year-old Pakistani man was admitted to a rheumatology unit with acute generalized polyarthritis. He had been in perfect health during three years working in England. Eight weeks before admission he had had an episode of "pleuritic" pain together with conjunctivitis and swelling of the hands and feet. About that time he had attended a dermatology outpatient clinic with a skin eruption and was treated for septic spots on the hands and legs.

Uhited Oxford Hospitals, Oxford

SHEILA POWELL, M.B., B.S., M.R.C.P., Registrar in Dermatology, The Slade Hospital

University of Oxford, Department of Human Anatomy, Oxford OX1 3QX

COLIN McDOUGALL, M.D., M.R.C.P., Research Assistant
He later lost weight and suffered from fever, nasal discharge, and epistaxis. On admission a diagnosis of Reiter's disease was considered, but the finding of splenomegaly together with the development of proteinuria and uraemia (blood urea, $246 \mathrm{mg} / 100 \mathrm{ml}$ ) led to a diagnosis of polyarteritis nodosa, and he was treated with prednisolone and chlorambucil. Skin and muscle biopsy, however, led to the finding of leprosy bacilli and typical lepromatous histology, and subsequently bacilli were also found on renal biopsy.

Case 2.-A 19-year-old Anglo-Indian woman who had lived in England since the age of six presented with a 10-day history of polyarthritis, swelling of the ankles, and a rash on the limbs. For some months she had noticed nasal discharge. She had purplish, round, tender lesions over the thighs and arms, tenderness and erythema with oedema of the lower legs, and altered sensation over the lateral aspect of the left lower leg. A diagnosis of erythema multiforme was made and treatment with corticosteroids was started. The eruption persisted and, though modified by corticosteroids, tended to relapse whenever the dosage was reduced. On further investigation a numb, pale area over the left calf was found, which had been present for about seven years, and the patient admitted that for some years she had noticed "snufing" and blockage of the nose. Two hypopigmented lesions on the left leg, vague annular lesions of various sizes on the trunk, and a butterfly rash on the face were also found on re-examination. There was thickening of the left lateral popliteal nerve with weakness in dorsiflexion of the left foot. Slit-skin smears and skin on biopsy were found to be strongly positive for Mycobacterium leprae and the histology was that of borderline lepromatous leprosy.

Case 3.-A 22-year-old Chinese woman from Hong Kong who had been in England for two years complained of an irritiant, persistent rash on the right hand for 18 months. It had later spread to the legs and face, and she had been treated intermittently for a fungus infection. She had noticed loss of sensation in the centre of some skin lesions. On admission she showed numerous raised, annular red lesions characteristic of borderline leprosy. Biopsy of skin and nerve tissue confirmed the diagnosis and bacilli were found in neural tissues.

Case 4.-A 44-year-old English bank employee who had worked in Northern Nigeria for many years had sought medical advice two years previously for a ring-shaped lesion on the right buttock, about $10 \mathrm{~cm}$ in diameter and with diminished sensation in the centre. He had been reassured that it was a patch of "burnt-out ringworm." Twenty months later he had developed nodular skin lesions widely distributed over his back and limbs. These were diagnosed as being "allergic" in origin, possibly from routine anti-malarial treatment. Though a medically-qualified Nigerian friend he met at a swimming bath suggested that the lesions might be leprosy the possibility of tinis diagnosis was not accepted until he returned to the United Kingdom for investigation, when slit-skin smears and biopsy of the skin and peripheral nerves showed advanced lepromatous leprosy with numerous morphologically solid-staining bacilli.

Case 5.-A 41-year-old man of Anglo-Indian parentage had developed "cramps" in the feet 12 years previously, while working in a gold mine in North India. Eight years after that he had lost sensation in his right forefinger. Two years later, after investigations which included skin biopsv, nasal smears, and a myelogram, he had been diagnosed in Madras as having syringomyelia. He then came to England, and two years later, when his neuropathv had progressed considerably, a diagnosis of leprosy was made after a nerve biopsy.

Case 6.-A 27-year-old woman who had recently arrived in Encland from the Gambia had been examined there because of a two-month history of a rash, nasal discharge, and epistaxis. She was reassured and diagnosed as having an "allergy." She then came to England, where slit-skin smears, biopsy of skin and nerves, and a profuse excretion of bacilli from blood-stained nasal discharges showed her to have lepromatous leprosy. 
Case 7.-A 34-year-old Indian engineer, who had passed a medical examination in India before leaving to work in the U.S.A., had complained two years later of a persistent nasal discharge and intermittent epistaxis, for which antihistamine nasal drops were prescribed. Six months later he had noticed scattered, indurated skin lesions and some swelling of the lobes of his ears. Skin biopsy had apparently shown no abnormality and a diagnosis of "allergy" made. Another doctor, however, confidently diagnosed leprosy. The patient came to England. Leprosy bacilli were present in large numbers in skin, nerve, scrotum, and nasal mucus. A 24hour nose-blow specimen yielded a count of $3.4 \times 10^{8}$ bacilli.

Case 8.-A Pakistani man living in England had developed "conjunctivitis" when aged 18. This had been diagnosed as trachoma, though scrapings were negative then and later. For over 18 months he attended the outpatient eye clinic with red, "irritable" eyes which did not respond to local treatment. He had then developed a more definite picture of iritis, and was found to have a butterfly rash on the cheeks and ulceration of his lower legs. On return from a nine-week visit to Pakistan he reported with a nodule on the left side of his nose and complained that for some months his nose had been continually "stuffed up." Slit-skin smears, nerve and skin biopsy specimens, and nose-blow mucus were all heavily positive for M. leprae, and the histology was that of uncontrolled lepromatous leprosy.

\section{Discussion}

In this small series several of the classic misdiagnoses, including syringomyelia, allergy, and mycosis have been encountered. Similar findings have been reported from France in a larger group of patients (Blanc and Nosny, 1970). The misdiagnosis of allergy, mycotic infections, and indeed of many other conditions would be avoided in most cases by simple testing for loss of sensation. Even in the absence of typical skin lesions syringomyelia should not give difficulty in practice, since the anaesthesia of leprosy is not dissociated, peripheral nerves are commonly enlarged and may be tender, and if necessary a nerve biopsy could prove the diagnosis. Two of our patients presented with a polyarthritis, and though one of them (case 1) had extraordinary features associated with a type 2 lepromatous reaction the occurrence of various arthropathies in leprosy is now being reported with increasing frequency (Lele et al., 1965; Karat et al., 1967; Manigand et al., 1969; Modi et al., 1969; Ramu and Balakrishnan, 1969) and leprosy should be considered in any unusual anthritis in a patient from an endemic area.

It is of interest that most of the lepromatous patients had had nasal symptoms for several months, in some cases much longer. Though there have been warnings that the results of examination of nasal smears or scrapings may be misleading in the diagnosis of leprosy, it is becoming increasingly apparent that in lepromatous leprosy the nose is not only a potent source of excretion of bacilli (Pedley, 1970; Davey and Rees, 1973) but also that the nasal tissues themselves may be heavily involved, sometimes in the absence of obvious signs elsewhere (Barton, 1973). These case histories show that closer attention to epistaxis, persistent nasal discharge, blockage, and "stuffiness" might have led to a much earlier diagnosis in several instances. The diagnostic problems are the old ones of not keeping the disease in mind; not testing for anaesthesia; and not reconsidering the diagnosis when a skin lesion persists despite straightforward treatment. To these a fourth point may be added-that nasal symptoms may be an early indication of lepromatous leprosy.

Finally, while acknowledging that retrospective diagnosis is easy, it must be recorded that there were features in the early presentation of all eight cases which if recognized could have led to the correat diagnosis of leprosy.

We wish to record our sincere thanks to medical colleagues who referred patients in this series to the Cochrane Annexe in Oxford. This work was supported by grants to Colin McDougall from the Medical Research Council and from the British Leprosy Relief Association (LEPRA).

\section{References}

Barton, R. P. E. (1973). Tenth International Leprosy Congress, Bergen, Session 6, 6/47.

Blanc, F., and Nosny, Y. (1970). Bulletin de la Société de Pathologie Exo-

tique, 63, 417. Geneeskunde, 113, 1686

Browne, S. G. (1965). Leprosy Review, 36, 157.

Canizares, O., and Andrade, R. (1969). Dermatologia Internacional, 8, 50.

Cochrane, R. G. (1947). A Practical Textbook of Leprosy, p. 82. London, Oxford University Press.

Cochrane, R. G. (1965). Leprosy Review, 36, 189.

Davey, T. F. (1942). Leprosy Review, 13, 3.

Davey, T. F., and Rees, R. J. W. (1973). Tenth International Leprosy Congress, Bergen, Session 6, 6/46.

Donner, R. S., and Shively, J. A. (1967). Annals of Internal Medicine. 67, 831 Fasal, P., (1958). Transactions of the Seventh International Congress of Leprology, Tokyo, p. 392.

Jopling, W. H. (1956). Central African fournal of Medicine, 2, 390.

Jopling, W. H. (1970). International Leprosy Colloquium, Borstel, Germany, Section F.25, p. 47.

Karat, A. B. A., Karat, S., Job, C. K., and Furness, M. A. (1967). Rritish Medical fournal, 3,770 .

Khanolkar, V. R. (1961). Leprosy Review, 32, 158.

Lele, R. D. Saineni, G. S, and Sharma, K. D. (1965). Fournal of the Association of Physicians of India, 13, 275.

Maniation of Physicians of India, B., and Deparis, M. (1969). Semaine des Hopitaux de Paris, 45, 543.

Modi, T. H., and Lele, R. D. (1969). Fournal of the Association of Physicians of India, 17, 247.

Pedley, J. C. (1970). Leprosy Review, 41, 31

Pfaltzgraff, R. E. (1967). Leprosy Review, 38, 15.

Ramu, G., and Balakrishnan, S. (1968). Leprosy in India, 40, 62.

Sinkovics, J. G., and Ibanez, M. L. (1970). Postgraduate Medicine, 47, 109. 